Trauma Surgery \& Acute Care Open

\title{
Age of thawed plasma does not affect clinical outcomes or biomarker expression in patients receiving prehospital thawed plasma: a PAMPer secondary analysis
}

\author{
Katherine M Reitz 다, ' Danielle S Gruen (1) , ${ }^{1}$ Frances Guyette, ${ }^{2}$ Joshua B Brown, ${ }^{1}$ \\ Mark H Yazer, ${ }^{3}$ Yoram Vodovotz, ${ }^{1}$ Pär I Johanssen, ${ }^{4}$ Jakob Stensballe, ${ }^{4}$ Brian Daley, ${ }^{5}$ \\ Richard S Miller, ${ }^{6}$ Brian G Harbrecht, ${ }^{7}$ Jeffrey Claridge, ${ }^{8}$ Herb A Phelan, ${ }^{9}$ \\ Matthew D Neal, ${ }^{1}$ Brian S Zuckerbraun, ${ }^{1}$ Jason L Sperry'
}

'Department of Surgery, University of Pittsburgh Medical Center, Pittsburgh, Pennsylvania, USA

Emergency Medicine, University of Pittsburgh, Pittsburgh,

Pennsylvania, USA

${ }^{3}$ Department of Pathology,

University of Pittsburgh and

the Institute for Transfusion

Medicine, Pittsburgh,

Pennsylvania, USA

${ }^{4}$ Capital Region Blood Bank,

Section for Transfusion Medicine, University of Copenhagen,

Kobenhavn, Denmark

${ }^{5}$ The University of Tennessee

Health Science Center, Memphis,

Tennessee, USA

${ }^{6}$ Surgery, Vanderbilt University

Medical Center, Nashville,

Tennessee, USA

'University of Louisville, Louisville, Kentucky, USA

${ }^{8}$ Surgery, MetroHealth Medical Center, Cleveland, Ohio, USA

${ }^{9}$ Surgery, The University of Texas Southwestern Medical Center,

Dallas, Texas, USA

Correspondence to

Dr Jason L Sperry; sperryj|@

upmc.edu

Received 16 November 2020 Revised 13 January 2021

Accepted 25 January 2021

(c) Author(s) (or their employer(s)) 2021. Re-use permitted under CC BY-NC. No commercial re-use. See rights and permissions. Published by BMJ.

To cite: Reitz KM, Gruen DS, Guyette F, et al. Trauma Surg Acute Care Open

2021:6:e000648.

\section{ABSTRACT}

Background Prehospital plasma administration during air medical transport reduces the endotheliopathy of trauma, circulating pro-inflammatory cytokines, and 30day mortality among traumatically injured patients at risk of hemorrhagic shock. No clinical data currently exists evaluating the age of thawed plasma and its association with clinical outcomes and biomarker expression postinjury.

Methods We performed a secondary analysis from the prehospital plasma administration randomized controlled trial, PAMPer. We dichotomized the age of thawed plasma creating three groups: standard-care, YOUNG (day 0-1) plasma, and OLD (day 2-5) plasma. We generated HRs and 95\% Cls for mortality. Among all patients randomized to plasma, we compared predicted biomarker values at hospital admission (TO) and 24 hours later (T24) controlling for key difference between groups with a multivariable linear regression. Analyses were repeated in a severely injured subgroup.

Results Two hundred and seventy-one patients were randomized to standard-care and 230 to plasma (40\% YOUNG, 60\% OLD). There were no clinically or statistically significant differences in demographics, injury, admission vital signs, or laboratory values including thromboelastography between YOUNG and OLD. Compared with standard-care, YOUNG (HR 0.66 (95\% Cl 0.41 to 1.07), $\mathrm{p}=0.09$ ) and OLD (HR 0.64 (95\% $\mathrm{Cl} 0.42$ to 0.96$), p=0.03$ ) plasma demonstrated reduced 30-day mortality. Among those randomized to plasma, plasma age did not affect mortality (HR $1.04(95 \% \mathrm{Cl}$ 0.60 to 1.82 ), $p=0.90$ ) and/or adjusted serum markers by plasma age at T0 or T24 ( $p>0.05)$. However, among the severely injured subgroup, OLD plasma was significantly associated with increased adjusted inflammatory and decreased adjusted endothelial biomarkers at T0.

Discussion Age of thawed plasma does not result in clinical outcome or biomarker expression differences in the overall PAMPer study cohort. There were biomarker expression differences in those patients with severe injury. Definitive investigation is needed to determine if the age of thawed plasma is associated with biomarker expression and outcome differences following traumatic injury.

Level of evidence II.

\section{INTRODUCTION}

Traumatic injury is a leading cause of death in the USA with detrimental societal and public health consequences. ${ }^{1}$ The resuscitation of patients who suffer traumatic injury continues to evolve and focuses on the prevention of coagulopathy through minimization of crystalloid infusion and early blood component transfusion. ${ }^{2-6}$ Despite the beneficial effects of these resuscitation advances, the rate of mortality continues to be high within the first hours of arrival to a trauma center and highlights the importance of interventions initiated early in the prehospital setting. ${ }^{7-12}$ The multicenter, randomized Prehospital Air Medical Plasma (PAMPer) trial randomized severely injured patients transported to a trauma center by helicopter emergency services to prehospital thawed plasma administration or standard-care. ${ }^{13}$ The administration of prehospital thawed plasma was safe, lowered 30-day mortality, and has been shown to potentially moderate the immune dysfunction and endotheliopathy of trauma. ${ }^{713}$

Although the benefits of prehospital thawed plasma administration in severely injured patients have been demonstrated, this intervention is potentially resource intensive due to the need of providing it in an uncross-matched fashion and the short shelflife of 5 days. ${ }^{14-16}$ This time window has the potential to result in significant plasma wastage and high financial costs when implemented in the prehospital arena. ${ }^{14}$ Further, animal studies have demonstrated that thawed plasma processing and the duration of time thawed (age of thawed plasma) can alter endothelial permeability, vascular stability, coagulation proteins, and microparticles necessary for immune and inflammatory regulation. ${ }^{17-19}$ However, the relationship between the age of thawed plasma and both associated clinical outcome and biomarker expression differences following injury has not been adequately characterized. The overall objective of the current secondary analysis was to determine if the age of thawed plasma was associated with outcome and biomarker expression differences using an existing study cohort. We hypothesized that the outcome benefits and biomarker expression would not be affected by the age of thawed plasma. 


\section{Methods}

We performed a secondary analysis using data and biomarker measurements derived from the PAMPer trial. ${ }^{1320}$ As previously described, the PAMPer trial enrolled patients transported via helicopter emergency services at risk of hemorrhagic shock. Randomization occurred at the level of the helicopter emergency services base, in 1-month blocks, to either standard of care resuscitation or $2 \mathrm{U}$ of either group $\mathrm{AB}$ or group $\mathrm{A}$ with low anti-B titer $(<1: 100)$ thawed plasma. The trial protocol mandated that both units of plasma were infused to completion, even if this required infusion to continue after arrival at the trauma center. In accordance with the American Association of Blood Banks guidelines, all thawed plasma had a 5-day period of validity. ${ }^{14-16}$ The temperature of the thawed units were monitored in blood bank-approved refrigerators at the helicopter emergency services bases and with adhesive blood temperature monitoring labels on the units in coolers when in flight. ${ }^{14}$ Any and all plasma units used by helicopter emergency services teams were replaced and unused units were exchanged prior to expiration dates. For plasma unit pairs that did not expire on the same day $(n=22)$, we assigned the plasma pair was assigned the longer thawed duration.

Inclusion criteria for PAMPer involved patients transported from the scene of trauma or referring facilities by participating helicopter emergency services to a PAMPer network trauma center at risk of hemorrhagic shock. Patient-specific parameters included severe hypotension (systolic blood pressure, $<70 \mathrm{~mm}$ $\mathrm{Hg}$ ) or hypotension (systolic blood pressure, 70-90 $\mathrm{mm} \mathrm{Hg}$ ) and tachycardia (heart rate $>108$ beats per minute) prior to arrival to the trauma center. Exclusion criteria included known pregnancy, prisoner status, penetrating injury to the head, asystole or cardiopulmonary resuscitation $(>5 \mathrm{~min})$, known objection to blood products.

In this secondary analysis, we included patients enrolled in PAMPer analyzed for primary outcome per the modified intention-to-treat protocol. Clinical outcomes were compared across three groups: (1) standard-care group; (2) plasma below median time thawed (0-1 days, YOUNG); (3) plasma equal to or above median time thawed (2-5 days, OLD). In sensitivity analysis, we also compared clinical outcomes of plasma group extremes, categorized as plasma above the median age (3-5 days, EXTREME OLD). For exploratory biomarker analysis, we excluded patients who were not allocated to the plasma group and who were unable to be sampled due to clinical care logistics of caring for the severely injured. We also performed a subgroup analysis in patients with the highest quartile of injury severity (Injury Severity Score >30) which has been characterized in prior PAMPer secondary analyses.?

Blood samples were collected, when feasible, from PAMPer trial patients on admission (TIME 0 (T0)) and at 24 (T24) hours. Twenty-one inflammatory mediators measured included interleukin (IL)-1ß, IL-2, IL-4, IL-5, IL-6, IL-7, IL-8，IL-9，IL-10, IL-17A, IL-7E (ie, IL-25), IL-21, IL-22, IL-23, IL-27, IL-33, monocyte chemoattractant protein $(\mathrm{MCP})-1$, INF-gamma (MIG), granulocyte-macrophage colony-stimulating factor (GM-CSF), and tumor necrosing factor (TNF) $-\alpha$. Seven cell damage and death markers included histone-complexed DNA (hcDNA), human S100 calcium-binding protein A10 (S100A10), soluble urokinase receptor (suPAR), syndecan-1, thrombomodulin (TM), vascular endothelial growth factor (VEGF), and adipokine. Syndecan-1, TM, and VEGF have a hypothesized association to trauma-related damage of the endothelial cell's glycocalyx, endothelium, and tight junction, respectively. ${ }^{21} 22$ Adipokine has a hypothesized association with restoration of endothelial cell function. Assays for inflammatory, damage, and those specific to endothelial cells were previously reported. ${ }^{7}$ Units for all IL, TNF- $\alpha$, MCP-1, MIG, and GM-CSF are in picograms per milliliter, except IL-23, which is in nanograms per milliliter. All cell damage and death marker units are in nanograms per milliliter, except VEGF which is in picograms per milliliter, and hcDNA are reported as relative units.

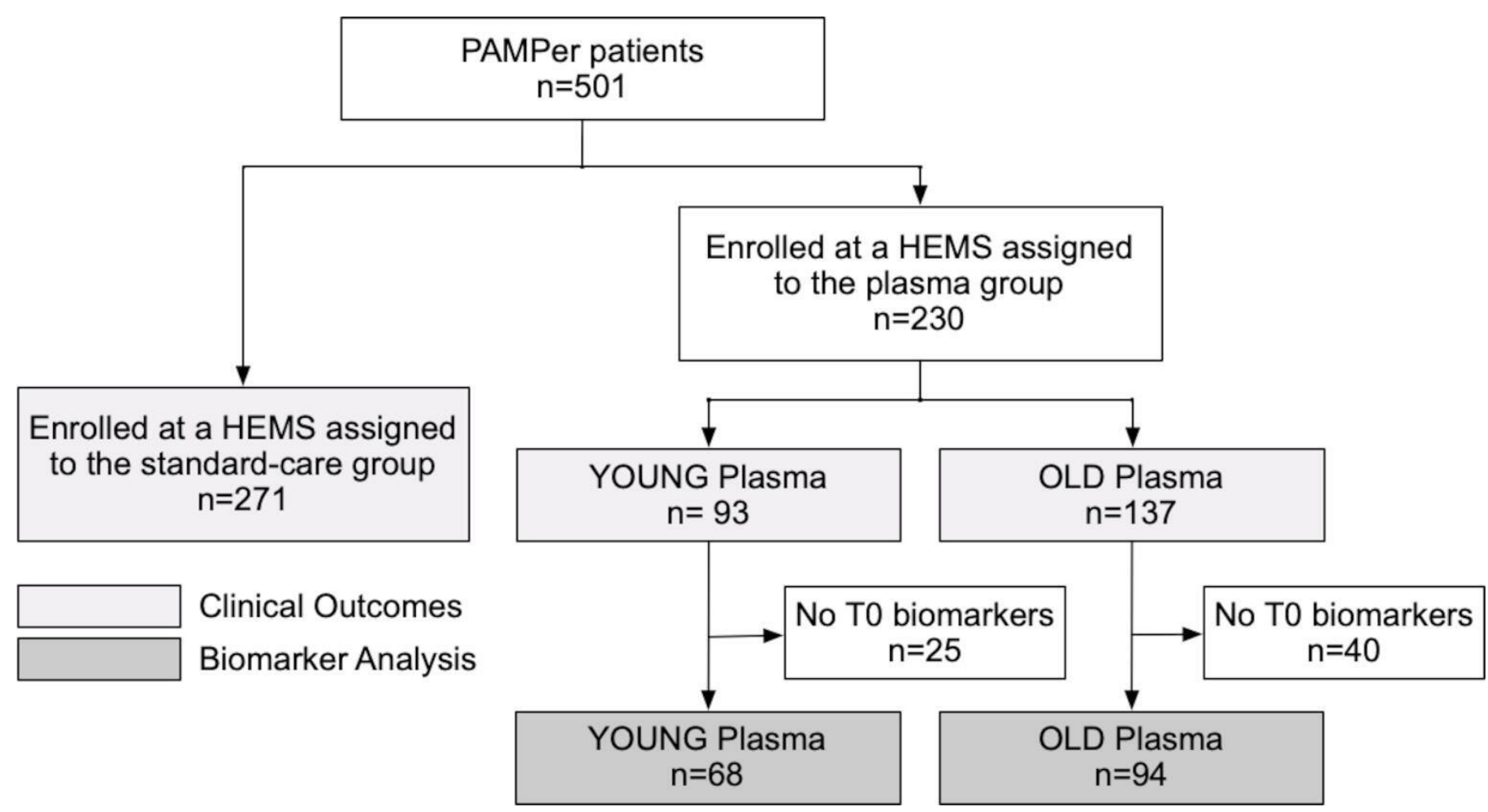

Figure 1 Principal cohort. HEMS, helicopter emergency services; PAMPer, Prehospital Air Medical Plasma; T0, time 0. 
Table 1 Patient and injury characteristics - principal analysis cohort $(n=501)$

\begin{tabular}{|c|c|c|c|}
\hline \multirow[b]{2}{*}{ Variable } & \multicolumn{2}{|l|}{ Plasma group } & \multirow[b]{2}{*}{$P$ value } \\
\hline & YOUNG & OLD & \\
\hline Demographics & $\mathrm{n}=93$ & $n=137$ & \\
\hline Age, years, mean (SD) & $45.7(17.7)$ & $45.3(17.2)$ & 0.84 \\
\hline Male gender, No. (\%) & $65(70)$ & $99(72)$ & 0.70 \\
\hline Race, No. (\%) & & & 0.21 \\
\hline White & $88(95)$ & $119(87)$ & \\
\hline Black & $4(4)$ & $10(7)$ & \\
\hline Other & $0(0)$ & $0(0)$ & \\
\hline Unknown & $0(0)$ & $2(1)$ & \\
\hline Hispanic, No. (\%) & $2(2.3)$ & $4(3.1)$ & 0.71 \\
\hline Current smoking, No. (\%) & $41(54)$ & $42(41)$ & 0.09 \\
\hline Body mass index, mean (SD) & $30.7(9.5)$ & $30.0(6.5)$ & 0.58 \\
\hline \multicolumn{4}{|l|}{ Prehospital and injury } \\
\hline Penetrating injury, №. (\%) & $20(22)$ & $26(19)$ & 0.64 \\
\hline Injury severity score, median (IQR) & $22.0(13.0,34.0)$ & $22.0(16.0,29.0)$ & 0.59 \\
\hline Traumatic brain injury, №. (\%) & $17(36.2)$ & $19(34.5)$ & 0.86 \\
\hline Hospital transfer, No. (\%) & $22(23.7)$ & $30(22.1)$ & 0.78 \\
\hline Prehospital interval, median (IQR) & $3(3.2)$ & $4(2.9)$ & 0.89 \\
\hline \multicolumn{4}{|l|}{ Hospital } \\
\hline Admission heart rate, mean (SD) & $105.2(31.7)$ & $101.9(28.9)$ & 0.41 \\
\hline Admission systolic blood pressure, mean (SD) & $100.7(39.2)$ & $100.7(40.8)$ & 1.00 \\
\hline Admission INR, median (IQR) & $1.2(1.1,1.4)$ & $1.2(1.1,1.3)$ & 0.58 \\
\hline Admission hemoglobin, median (IQR) & $10.9(9.0,13.3)$ & $10.8(9.4,12.7)$ & 0.88 \\
\hline \multicolumn{4}{|l|}{ Admission rapid thromboelastography } \\
\hline Lysis at 30 min, \%, median (IQR) & $0.1(0.0,1.4)$ & $0.2(0.0,1.1)$ & 0.75 \\
\hline Max amplitude, min, median (IQR) & $59.6(52.0,63.5)$ & $56.4(47.8,64.7)$ & 0.48 \\
\hline Alpha angle, degrees, median (IQR) & $70.8(62.3,74.9)$ & $70.2(61.6,74.7)$ & 0.60 \\
\hline K-time, min, median (IQR) & $1.8(1.2,2.7)$ & $1.8(1.2,3.0)$ & 0.95 \\
\hline Activated clotting time, median (IQR) & $113.0(97.0,136.0)$ & $113.0(105.0,136.0)$ & 0.46 \\
\hline PRBC in 24 hours, median (IQR) & $3.0(2.0,6.0)$ & $2.0(0.0,7.0)$ & 0.35 \\
\hline Plasma in 24 hours, median (IQR) & $0.0(0.0,3.0)$ & $0.0(0.0,3.0)$ & 0.90 \\
\hline Platelets in 24 hours, median (IQR) & $0.0(0.0,1.0)$ & $0.0(0.0,1.0)$ & 0.63 \\
\hline Crystalloid in 24 hours, median (IQR) & $4434(2372,6200)$ & $4375(2200,6600)$ & 0.96 \\
\hline Multisystem organ failure, №. (\%) & $61(65.6)$ & $84(61.3)$ & 0.51 \\
\hline
\end{tabular}

No., number; PRBC, packed red blood cells.

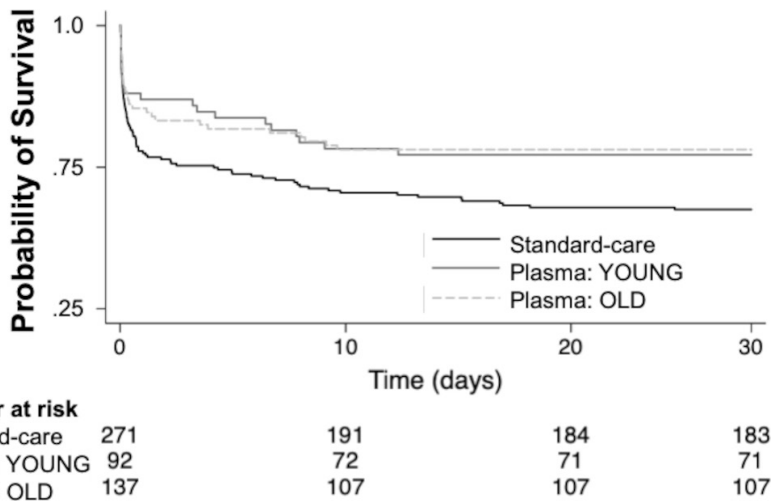

Figure 2 Kaplan-Meier survival analysis for the primary cohort (panel $A ; n=501$ ) and subgroup (panel $B ; n=127$ ).
To understand the characteristics of patients based on the treatment groups, we used descriptive statistics to compare patient demographics and injuries, prehospital and transport, and hospital admission patient factors including laboratory values. We evaluated differences in 30-day survival between treatment groups with Kaplan-Meier curves and associated log-rank testing for overall statistical significance. We then generated unadjusted HRs and associated 95\% CI to compare the differences between specific treatment groups (standard-care vs YOUNG; standardcare vs OLD; YOUNG vs OLD) in addition to sensitivity analysis groups (YOUNG vs EXTREME OLD).

All multivariable linear regression analyses adjusted for Injury Severity Score, prehospital systolic blood pressure $<70 \mathrm{~mm} \mathrm{Hg}$, Glasgow Coma Score, and resuscitation volumes (ie, plasma, blood, and crystalloid), and international ratio (INR) on hospital arrival with a robust variance estimator and were subject to appropriate testing. We calculated the linear prediction from 
Table 2 Model estimation coefficients for markers at T0-YOUNG vs OLD plasma age

\begin{tabular}{|c|c|c|c|c|c|c|c|c|}
\hline \multicolumn{5}{|c|}{ Plasma group $(n=137)$} & \multicolumn{4}{|c|}{ ISS $>30$ plasma subgroup $(n=56)$} \\
\hline \multirow[b]{2}{*}{ Marker } & \multirow[b]{2}{*}{ Coefficient } & \multicolumn{2}{|l|}{$95 \% \mathrm{Cl}$} & \multirow[b]{2}{*}{$P$ value } & \multirow[b]{2}{*}{ Coefficient } & \multicolumn{2}{|l|}{$95 \% \mathrm{Cl}$} & \multirow[b]{2}{*}{$P$ value } \\
\hline & & Lower limit & Upper limit & & & Lower limit & Upper limit & \\
\hline IL-1b & 0.456 & -2.762 & 3.673 & 0.781 & 4.394 & 1.027 & 7.761 & 0.011 \\
\hline IL-2 & 0.064 & -1.791 & 1.919 & 0.946 & 2.414 & 0.262 & 4.565 & 0.028 \\
\hline IL-4 & -20.063 & -66.499 & 26.373 & 0.397 & 39.6 & 13.482 & 65.718 & 0.003 \\
\hline IL-5 & -2.664 & -8.369 & 3.041 & 0.36 & 2.667 & 0.921 & 4.413 & 0.003 \\
\hline IL-6 & 35.696 & -158.755 & 230.147 & 0.719 & 7.664 & -384.257 & 399.586 & 0.969 \\
\hline IL-7 & 4.116 & -2.281 & 10.513 & 0.207 & 11.494 & -0.96 & 23.947 & 0.07 \\
\hline IL-8 & 6.21 & -11.606 & 24.026 & 0.494 & -28.604 & -86.985 & 29.776 & 0.337 \\
\hline IL-9 & 2.725 & -18.023 & 23.473 & 0.797 & 25.238 & 2.171 & 48.304 & 0.032 \\
\hline IL-10 & 60.645 & -102.332 & 223.622 & 0.466 & -19.358 & -285.774 & 247.058 & 0.887 \\
\hline IL-17a & 1.457 & -3.876 & 6.79 & 0.592 & 6.27 & 0.1 & 12.439 & 0.046 \\
\hline IL-17e & 69.021 & -38.997 & 177.039 & 0.21 & 308.579 & 103.895 & 513.264 & 0.003 \\
\hline IL-21 & 9.08 & -22.34 & 40.5 & 0.571 & 47.905 & 11.959 & 83.852 & 0.009 \\
\hline IL-22 & 104.23 & -248.61 & 457.071 & 0.563 & 715.174 & 165.919 & 1264.429 & 0.011 \\
\hline IL-23 & 1.042 & -6.305 & 8.39 & 0.781 & 12.725 & 5.139 & 20.311 & 0.001 \\
\hline IL-27 & 51.292 & -453.426 & 556.009 & 0.842 & 977.828 & 137.887 & 1817.769 & 0.023 \\
\hline IL-33 & 10.925 & -39.263 & 61.112 & 0.67 & 95.05 & 32.919 & 157.18 & 0.003 \\
\hline GM-CSF & -7.832 & -20.563 & 4.9 & 0.228 & 14.629 & 5.478 & 23.78 & 0.002 \\
\hline MCP-1 & 366.455 & -29.438 & 762.349 & 0.07 & -28.592 & -912.995 & 855.811 & 0.949 \\
\hline MIG & 4285.834 & -3033.508 & 11605.176 & 0.251 & 14107.398 & -9169.341 & 37384.137 & 0.235 \\
\hline TNF- $\alpha$ & 0.964 & -11.013 & 12.94 & 0.875 & 5.174 & -28.073 & 38.421 & 0.76 \\
\hline Adiponectin & -1736.773 & -3848.6 & 375.055 & 0.107 & -355.837 & -2733.742 & 2022.067 & 0.769 \\
\hline hcDNA & -8.264 & -18.546 & 2.017 & 0.115 & -34.837 & -49.677 & -19.998 & 0 \\
\hline S100A10 & -0.717 & -2.027 & 0.593 & 0.284 & -0.892 & -2.003 & 0.218 & 0.115 \\
\hline sUPAR & -0.374 & -0.924 & 0.177 & 0.183 & 0.351 & -0.64 & 1.343 & 0.487 \\
\hline Syndecan-1 & 2.035 & -23.878 & 27.949 & 0.878 & -54.767 & -96.663 & -12.872 & 0.01 \\
\hline TM & 0.103 & -1.204 & 1.41 & 0.877 & 0.92 & -1.079 & 2.919 & 0.367 \\
\hline VEGF & 81.405 & -103.409 & 266.218 & 0.388 & 2.333 & -276.162 & 280.829 & 0.987 \\
\hline
\end{tabular}

GM-CSF, granulocyte-macrophage colony-stimulating factor; hCDNA, histone-complexed DNA; IL, interleukin; ISS, Injury Severity Score; MCP-1, monocyte chemoattractant protein; MIG, INF-gamma; S100A10, human S100 calcium-binding protein A10; suPAR, soluble urokinase receptor; TM, thrombomodulin; TNF- $\alpha$, tumor necrosing factor- $\alpha$; VEGF, vascular endothelial growth factor.

the fitted models for each biomarker for each patient. In the subgroup, predicted biomarkers were presented as mean and corresponding $\mathrm{SD}$ values for each age of plasma group.

We expressed continuous variables as mean (SD) or median (IQR) and categorical variables as frequencies (percent). Differences were tested with Student's t-tests or Kruskal-Wallis and $\chi^{2}$ with a $\mathrm{p}$ value $<0.05$ considered statistically significant on twosided testing. No adjustments were made for multiple comparisons. All data were analyzed with Stata V.15.1 (StataCorp). Patient enrollment, informed consent, and data collection were in compliance with the PAMPer trial protocol and regulatory oversite as registered with ClinicalTrials.gov (NCT01818427). This study was approved under an Emergency Exception From Informed Consent protocol from the Human Research Protection Office of the US Army Medical Research and Material Command and by the appropriate institutional review boards. ${ }^{13}$ The use of these data in secondary analysis was reviewed by the University of Pittsburgh Institutional Review Board (STUDY20070145).

\section{RESULTS}

\section{Patient cohort}

The final modified intention-to-treat cohort analyzed in PAMPer included 501 patients with $271(54 \%)$ enrolled at a helicopter emergency services assigned to the standard-care group and 230 $(46 \%)$ enrolled at a helicopter emergency services assigned to the plasma group. For those in the plasma group, the median age of thawed plasma was 2 days (IQR, 1-3); therefore, 93 (40\%) received plasma thawed for 0 to 1 days (YOUNG) and 137 (60\%) for 2 to 5 days (OLD; figure 1). Although patients were not stratified or randomized at the level of thawed plasma age, there were no clinically or statistically significant differences in demographics, injury characteristics and severity, admission vital signs, and laboratory values including thromboelastography measurements between YOUNG and OLD plasma age groups (table 1).

\section{Post-Trauma survival}

There were 88 (32\%), 21 (23\%), and $30(22 \%)$ deaths at 30 days for patients receiving standard-care, YOUNG plasma, and OLD plasma (figure $2 ; \mathrm{p}=0.047$ ). Consistent with the primary outcome results in PAMPer, prehospital plasma reduced the hazard of 30-day mortality by approximately $35 \%$ for both plasma age groups (YOUNG, HR 0.66 (95\% CI 0.41 to 1.07), $\mathrm{p}=0.09$ and OLD, HR $0.64(95 \%$ CI 0.42 to 0.96$), \mathrm{p}=0.03)$ when compared with standard of care. The YOUNG plasma cohort contained the fewest patients and did not reach statistical 
Table 3 Patient and injury characteristics—subgroup (Injury Severity Score $>30, n=127$ )

\begin{tabular}{|c|c|c|c|}
\hline \multirow[b]{2}{*}{ Variable } & \multicolumn{2}{|l|}{ Plasma group } & \multirow[b]{2}{*}{$P$ value } \\
\hline & YOUNG & OLD & \\
\hline Demographics & $n=30$ & $\mathrm{n}=34$ & \\
\hline Age, years, mean (SD) & $40.0(14.8)$ & $41.9(19.4)$ & 0.65 \\
\hline Male gender, No. (\%) & $18(60)$ & $23(68)$ & 0.52 \\
\hline Race, No. (\%) & & & 0.15 \\
\hline White & $29(97)$ & $29(85)$ & \\
\hline Black & $0(0)$ & $4(12)$ & \\
\hline Unknown & $1(3)$ & $1(3)$ & \\
\hline Hispanic, No. (\%) & $0(0.0)$ & $0(0.0)$ & 0.34 \\
\hline Current smoking, №. (\%) & $13(59)$ & $13(54)$ & 0.74 \\
\hline Body mass index, mean (SD) & $30.2(9.8)$ & $29.6(7.4)$ & 0.84 \\
\hline \multicolumn{4}{|l|}{ Prehospital and injury } \\
\hline Penetrating injury, No. (\%) & $4(13)$ & $3(9)$ & 0.56 \\
\hline Injury severity score, median (IQR) & $43.0(35.0,50.0)$ & $41.0(34.0,45.0)$ & 0.26 \\
\hline Traumatic brain injury, No. (\%) & $8(50.0)$ & $7(58.3)$ & 0.66 \\
\hline Admission heart rate, mean (SD) & $112.5(29.6)$ & $98.9(34.1)$ & 0.10 \\
\hline Admission systolic blood pressure, mean (SD)) & $91.8(33.1)$ & $94.3(51.4)$ & 0.83 \\
\hline Hospital transfer, №. (\%) & $6(20.0)$ & $7(21.2)$ & 0.47 \\
\hline Prehospital interval, median (IQR) & $41.5(32.8,54.6)$ & $40.4(32.8,48.1)$ & 0.48 \\
\hline \multicolumn{4}{|l|}{ Hospital } \\
\hline Admission INR, median (IQR) & $1.2(1.1,1.5)$ & $1.2(1.1,1.3)$ & 0.72 \\
\hline Admission hemoglobin, median (IQR) & $11.2(10.3,12.6)$ & $10.2(8.9,11.4)$ & 0.084 \\
\hline \multicolumn{4}{|l|}{ Admission rapid thromboelastography } \\
\hline Lysis at $30 \mathrm{~min}, \%$, median (IQR) & $0.2(0.0,0.9)$ & $0.2(0.0,2.5)$ & 0.85 \\
\hline Max amplitude, min, median (IQR) & $59.6(53.0,61.5)$ & $55.0(49.1,60.6)$ & 0.42 \\
\hline Alpha angle, degrees, median (IQR) & $70.0(68.5,73.9)$ & $68.2(61.9,74.2)$ & 0.79 \\
\hline K-time, min, median (IQR) & $1.8(1.4,1.8)$ & $2.0(1.5,2.7)$ & 0.65 \\
\hline Activated clotting time, median (IQR) & $117.0(109.0,124.5)$ & $113.0(89.0,136.0)$ & 0.64 \\
\hline PRBC in 24 hours, median (IQR) & $4.0(2.0,11.0)$ & $4.5(2.0,10.0)$ & 0.90 \\
\hline Plasma in 24 hours, median (IQR) & $2.0(0.0,4.0)$ & $0.5(0.0,4.0)$ & 0.95 \\
\hline Platelets in 24 hours, median (IQR) & $0.0(0.0,1.0)$ & $0.0(0.0,1.0)$ & 0.78 \\
\hline Crystalloid in 24 hours, median (IQR) & $5110.0(3200.0,6647.0)$ & $4437.5(1500.0,7050.0)$ & 0.49 \\
\hline Multisystem organ failure, №. (\%) & $20(66.7)$ & $25(73.5)$ & 0.55 \\
\hline
\end{tabular}

INR, international ratio; No., number; PRBC, packed red blood cells.

significance but demonstrated a trend. Most importantly, the age of thawed plasma overall and at age extremes, 3 to 5 days (EXTREME OLD $(\mathrm{n}=78)$ ) did not affect 30-day mortality (YOUNG vs OLD, HR 1.04 (95\% CI 0.60 to 1.82), $\mathrm{p}=0.90$; YOUNG vs EXTREME OLD, HR 0.89 (95\% CI 0.47 to 1.49 ), $\mathrm{p}=0.72$ ).

\section{Biomarker evaluation}

Among patients in the plasma group $(n=230)$ with data available for biomarker analysis $(n=165$; figure 1$)$, in both univariate comparison (data not shown) and multivariable linear regression there were no clinically significant differences in biomarkers between plasma age groups at T0 (table 2) or T24 (online supplemental digital content table 1$)$.

There were a total of $64(50 \%)$ patients allocated to the plasma arm who had an Injury Severity Score $>30$ (mean age 41 years (SD 17), 23 males (68\%), mean Injury Severity Score 45 (SD 13)), of which 30 (47\%) received YOUNG and 34 (53\%) OLD plasma. There were no differences in demographics, injury, prehospital, or hospital admission between groups (table 3). At
30 days, $10(33 \%)$ patients receiving YOUNG plasma and 13 (38\%) patients receiving OLD plasma died (HR 1.2 (95\% CI 0.51 to 2.69$), \mathrm{p}=0.69)$ and $20(67 \%)$ of YOUNG plasma and $25(73 \%)$ of old plasma patients had multisystem organ failure $(\mathrm{p}=0.55)$. Among patients with data available for biomarker analysis $(n=46(72 \%))$, there were statistically significant differences between adjusted biomarker values at T0 (table 2) and T24 (online supplemental digital content table 1). At T0, patients who received OLD plasma had a higher mean circulating level of cytokine biomarkers when compared with YOUNG plasma, including those associated with the innate immune system and acute respiratory distress syndrome after trauma, IL- $1 \beta$; type 2 cytokine profiles associated with nosocomial infection-related complications and multiple system organ failure including IL-4, IL-5, IL-9, and IL-3323 24 ; type 17 immune cell production of IL-17A and IL-17E which have been associated with both pathologic (GM-CSF) and protective (IL-22) responses ${ }^{25}{ }^{26}$; and increased lymphoid mediators including IL-2, IL-4, IL-5, IL-17a, IL-21, IL-22, and IL-23 (figure 3). ${ }^{23}{ }^{27}$ However, patients who received OLD plasma had lower mean circulating damage and 

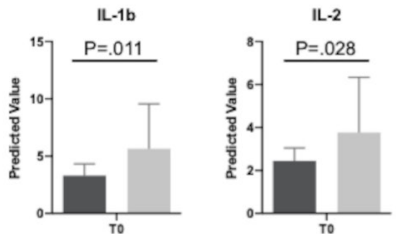

IL-8
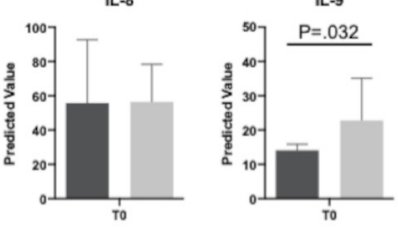

IL-22
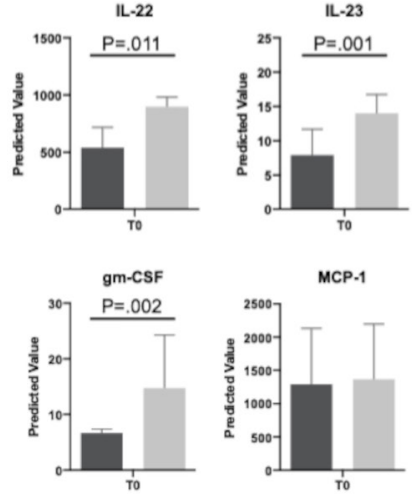

Syndican-1
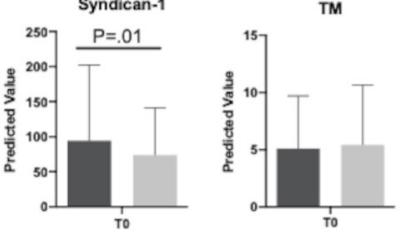


IL-10

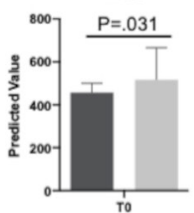

IL-27

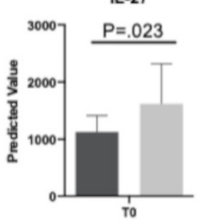

MIO

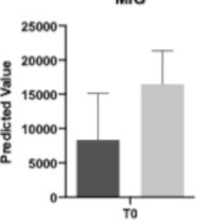

NF-a
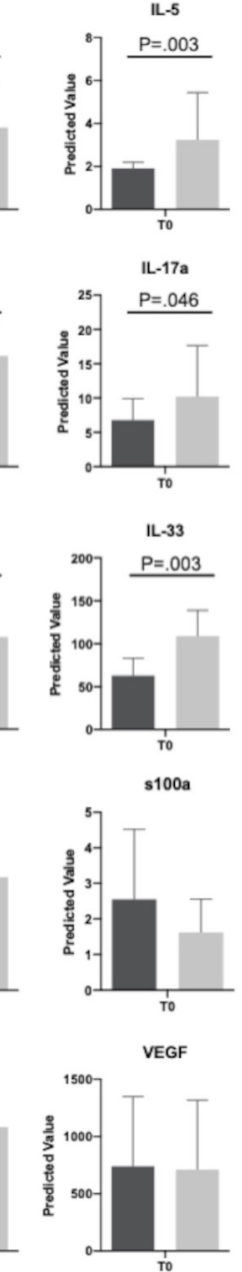
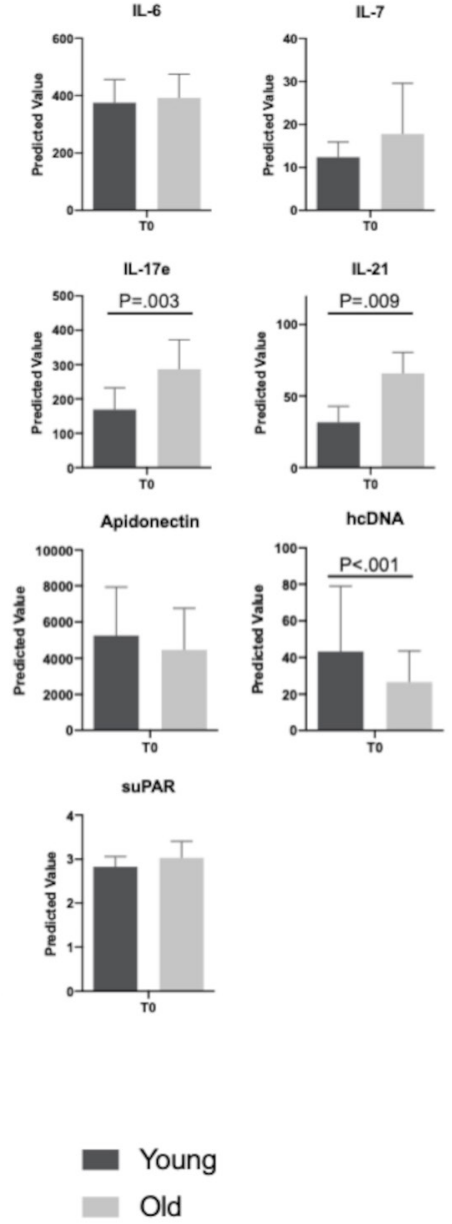

Figure 3 Adjusted T0 markers for subgroup (Injury Severity Score $>30 ; n=56$ ). Mean adjusted marker values estimated using linear regression controlling for Injury Severity Score, hospital admission Injury Severity Score, presence of a systolic blood pressure $<70 \mathrm{~mm} \mathrm{Hg}$, international ratio, and transfusions with error bars representing the SD and statistically significant co-efficient $p$ values. Units for all interleukins, TNF- $\alpha$, MCP-1, MIG, and GM-CSF are in pg/mL, except IL-23, which is in $\mathrm{ng} / \mathrm{mL}$. All cell death marker units are in $\mathrm{ng} / \mathrm{mL}$, except VEGF which is in $\mathrm{pg} / \mathrm{mL}$. DNA (histonecomplexed) is reported as relative units. GM-CSF, granulocyte-macrophage colony-stimulating factor; hcDNA, histone-complexed DNA; IL, interleukin; MCP-1, monocyte chemoattractant protein; MIG, INF-gamma; s100a, human S100 calcium-binding protein A10; suPAR, soluble urokinase receptor; TM, thrombomodulin; TNF- $\alpha$, tumor necrosing factor- $\alpha$; VEGF, vascular endothelial growth factor.

death cell markers hcDNA and Syndican-1 when compared with YOUNG plasma. These trends continued at T24, yet statistical significance was not maintained (online supplemental digital content table 1).

\section{DISCUSSION}

Significant advances in trauma resuscitation have occurred over the last decade with an increasing focus on early interventions provided in the prehospital and early phase of trauma center care. These early interventions are associated with improved outcomes, yet their underlying mechanisms of action in some cases are poorly characterized. Refinement of these interventions to provide maximal benefit necessitates a greater understanding of these mechanisms and those specific intervention facets which are associated with the most robust outcome benefit. In the current secondary analysis of the multicenter, randomized PAMPer trial, we found that the mortality benefit associated with prehospital plasma administration following severe injury was not altered by the duration of time the plasma was thawed. Among all patients randomized to the plasma group, biomarker expression was unaffected by the age of thawed plasma. Interestingly, our exploratory analysis of patients with the highest quartile of injury severity (Injury Severity Score $>30$ ) did demonstrate that the age of thawed plasma may be associated with differential cytokine and endothelial cell injury biomarker expression. Plasma thawed for a longer duration ( $2-5$ days; OLD) demonstrated altered biomarker expression when compared with plasma thawed for a shorter duration (0-1 days; YOUNG).

Prior studies looking at ex vivo measurements of thawed plasma have demonstrated differences in the hemostatic potential with increased storage time out to 5 days. ${ }^{28} 29$ A decline in beneficial microparticles, thought to be principally derived from platelets, has been shown to be primarily responsible for this reduction in the hemostatic capability of stored thawed plasma. ${ }^{17}$ Animal studies have demonstrated that aged plasma results in clinical outcome differences including higher mortality relative to freshly thawed plasma. ${ }^{28}$ Despite this prior literature, the results of the current analysis first verify the safety and efficacy of thawed plasma out to 5 days relative to clinical outcomes including 30-day mortality, when compared with standard prehospital resuscitation or when OLD and YOUNG plasma w compared. 
When both cytokine and endothelial cell injury biomarkers were characterized for the entire study cohort, there were no expression differences found when measured on arrival or at 24 hours post admission. These biomarker results corroborate the lack of clinical outcome differences for the overall study cohort. We have recently demonstrated in the PAMPer study cohort that plasma attenuates inflammatory cytokine and endothelial cell injury biomarkers relative to standard-care patients (who did not receive prehospital plasma) and these differences were most robust in the severely injured cohort (Injury Severity Score $>30) .{ }^{79}$ When we looked at biomarker expression in the plasma group alone across the different thawed plasma ages (OLD vs YOUNG) in this same severely injured cohort, we again found differences in biomarker expression early after injury. Although underpowered for definitive comparison, these biomarker expression differences did not correspond to any significant mortality outcome differences across the age of thawed plasma in these severely injured patients.

The current analysis may be underpowered to detect any significant mortality differences across the age of thawed plasma due to the smaller sample size of the subgroups. It may also be that any diminution of the hemostatic potential of thawed plasma as it approaches the 5- day period may be apparent in experimental models but is insignificant in clinical practice. For the severely injured subgroup, these exploratory biomarker expression differences may be simply related to differences across the patient population themselves and the small sample size of the subgroups. Alternatively, the biomarker expression differences may be a demonstration that the age of thawed plasma plays an effect on the immune response to injury, specifically in the most critically injured patients.

There are limitations of the current analysis. First, the study is a secondary analysis of a clinical trial which was not prespecified and data were not specifically collected to characterize the thawed plasma and associated outcomes. The subgroups were not specifically randomized and are underpowered for definitive comparison. The subgroups although were shown to be similar in demographics, injury characteristics, and severity, there may be unmeasured or unknown confounders that are responsible for the current findings presented. Biomarkers were measured at admission within the first few hours for the majority of patients, yet the prehospital time and time of injury for an individual patient was highly variable and unable to be controlled for. There exists the potential that biomarker expression may be confounded by this differential time of injury across patients. Finally, these results are exploratory and further research is needed to determine if these biomarker expression differences associated with OLD thawed plasma are reproducible and if they are associated with poor outcomes compared with YOUNG thawed plasma.

In conclusion, the results of the current analysis demonstrate that the age of thawed plasma does not result in significant clinical outcome or biomarker expression differences in the overall PAMPer study cohort. There were biomarker expression differences found in those patients with the highest quartile of injury severity. Although these biomarker expression differences did not manifest in any clinically apparent outcome differences, further definitive investigation is needed to determine if the age of thawed plasma is associated with biomarker expression and outcome differences following traumatic injury.

Contributors All authors contributed to this manuscript.
Funding This work was supported by the US Department of Defense (USAMRAA, W81XWH-12-2-0028 and USAMRAA, W81XWH-12-2-0023), the National Institute of Health (5T32HL0098036), and L30 AG064730 Institute of Aging.

Competing interests None declared.

Patient consent for publication Not required.

Provenance and peer review Not commissioned; externally peer reviewed.

Data availability statement No data are available. A subset of data are available on ClinicalTrials.gov (NCT01818427).

Open access This is an open access article distributed in accordance with the Creative Commons Attribution Non Commercial (CC BY-NC 4.0) license, which permits others to distribute, remix, adapt, build upon this work non-commercially, and license their derivative works on different terms, provided the original work is properly cited, appropriate credit is given, any changes made indicated, and the use is non-commercial. See: http://creativecommons.org/licenses/by-nc/4.0/.

\section{ORCID iDs}

Katherine M Reitz http://orcid.org/0000-0002-9397-321X

Danielle S Gruen http://orcid.org/0000-0003-1019-4390

\section{REFERENCES}

1 Centers for Disease Control and Prevention. Leading causes of death reports, 1981-2018. Web-based Injury Statistics Query and Reporting System (WISQARS). 2020. https://webappa.cdc.gov/sasweb/ncipc/leadcause.html (Accessed 6 Jan 2020).

2 Mattox KL, Maningas PA, Moore EE, Mateer JR, Marx JA, Aprahamian C, Burch $J M$, Pepe PE. Prehospital hypertonic saline/dextran infusion for post-traumatic hypotension. The U.S.A. multicenter trial. Ann Surg 1991;213:482-91.

3 Bickell WH, Wall MJ, Pepe PE, Martin RR, Ginger VF, Allen MK, Mattox KL. Immediate versus delayed fluid resuscitation for hypotensive patients with penetrating torso injuries. N Engl J Med 1994;331:1105-9.

4 Holcomb JB, Tilley BC, Baraniuk S, Fox EE, Wade CE, Podbielski JM, del Junco DJ, Brasel KJ, Bulger EM, Callcut RA, et al. Transfusion of plasma, platelets, and red blood cells in a 1:1:1 vs a 1:1:2 ratio and mortality in patients with severe trauma: the PROPPR randomized clinical trial. JAMA 2015;313:471-82.

5 Holcomb JB, del Junco DJ, Fox EE, Wade CE, Cohen MJ, Schreiber MA, Alarcon LH, Bai Y, Brasel KJ, Bulger EM, et al. The prospective, observational, multicenter, major trauma transfusion (PROMMTT) study: comparative effectiveness of a time-varying treatment with competing risks. JAMA Surg 2013;148:127-36.

6 Spinella PC, Holcomb JB. Resuscitation and transfusion principles for traumatic hemorrhagic shock. Blood Rev 2009;23:231-40.

7 Gruen DS, Brown JB, Guyette FX, Vodovotz Y, Johansson PI, Stensballe J, Barclay DA, Yin J, Daley BJ, Miller RS, et al. Prehospital plasma is associated with distinct biomarker expression following injury. JCI Insight 2020;5:135350. [Epub ahead of print: 2304 2020]

8 Shackelford SA, Del Junco DJ, Powell-Dunford N, Mazuchowski EL, Howard JT, Kotwal RS, Gurney J, Butler FK, Gross K, Stockinger ZT. Association of prehospital blood product transfusion during medical evacuation of combat casualties in Afghanistan with acute and 30-day survival. JAMA 2017;318:1581-91.

9 Sperry JL, Guyette FX, Brown JB, Yazer MH, Triulzi DJ, Early-Young BJ, Adams PW, Daley BJ, Miller RS, Harbrecht BG, et al. Prehospital plasma during air medical transport in trauma patients at risk for hemorrhagic shock. N Engl J Med Overseas Ed 2018:379:315-26.

10 Reitz KM, Moore HB, Guyette FX, Sauaia A, Pusateri AE, Moore EE, Hassoune A, Chapman MP, Daley BJ, Miller RS. Prehospital plasma in injured patients is associated with survival principally in blunt injury. J Trauma Acute Care Surg 2019;1.

11 Brown J, Rosengart M, Billiar T, Peitzman A, Sperry J. Distance matters: effect of geographic trauma system resource organization on fatal motor vehicle collisions. Physiol Behav 2017;176:139-48.

12 Fox EE, Holcomb JB, Wade CE, Bulger EM, Tilley BC, . PROPPR Study Group. Earlier endpoints are required for hemorrhagic shock trials among severely injured patients. Shock 2017:47:567-73.

13 Sperry JL, Guyette FX, Brown JB, Yazer MH, Triulzi DJ, Early-Young BJ, Adams PW, Daley BJ, Miller RS, Harbrecht BG, et al. Prehospital plasma during air medical transport in trauma patients at risk for hemorrhagic shock. N Eng/ J Med 2018;379:315-26.

14 Adams PW, Warren KA, Guyette FX, Yazer MH, Brown JB, Daily BJ, Miller RS, Harbrecht BG, Claridge JA, Phelan HA, et al. Implementation of a prehospital air medical thawed plasma program: is it even feasible? J Trauma Acute Care Surg 2019;87:1077-81.

15 Triulzi DJ. AABB contributions to plasma safety. Transfusion 2012;52 Suppl 1:5S-8.

16 Huestis DW. AABB guidelines and proposed standards. J Clin Apher 1985:2:306-10.

17 Kriebardis AG, Antonelou MH, Georgatzakou HT, Tzounakas VL, Stamoulis KE, Papassideri IS. Microparticles variability in fresh frozen plasma: preparation protocol and storage time effects. Blood Transfus 2016;14:228-37.

18 Matijevic N, Kostousov V, Wang Y-WW, Wade CE, Wang W, Letourneau P, Hartwell E, Kozar R, Ko T, Holcomb JB. Multiple levels of degradation diminish hemostatic potential of thawed plasma. J Trauma 2011;70:71-80. 
19 Pati S, Matijecic N, Doursout M-F, Ko T, Coa Y, Deng X, Kozar R, Hartwell E, Conyers J, Holcomb J. Protective effects of fresh frozen plasma on vascular endothelial permeability, coagulation, and resuscitation after hemorrhagic shock are time dependent and diminish between days 0 and 5 after thaw. J Trauma 2009;2010:1-17.

20 Brown JB, Guyette FX, Neal MD, Claridge JA, Daley BJ, Sperry JL. Taking the blood bank to the field: the design and rationale of the Prehospital Air Medical Plasma (PAMPer) trial. J Autism Dev Disord 2017:47:549-62.

21 Johansson PI, Henriksen HH, Stensballe J, Gybel-Brask M, Cardenas JC, Baer LA, Cotton BA, Holcomb JB, Wade CE, Ostrowski SR. Traumatic endotheliopathy: a prospective observational study of 424 severely injured patients. Ann Surg 2017; 265:597-603.

22 Peng Z, Pati S, Potter D, Brown R, Holcomb JB, Grill R, Wataha K, Park PW, Xue H, Kozar RA. Fresh frozen plasma lessens pulmonary endothelial inflammation and hyperpermeability after hemorrhagic shock and is associated with loss of syndecan 1. Shock 2013;40:195-202.

23 Xu J, Guardado J, Hoffman R, Xu H, Namas R, Vodovotz Y, Xu L, Ramadan M, Brown J, Turnquist HR, et al. IL33-mediated ILC2 activation and neutrophil IL5 production in the lung response after severe trauma: a reverse translation study from a human cohort to a mouse trauma model. PLoS Med 2017;14:e1002365-27.
24 Huber-Lang M, Lambris JD, Ward PA. Innate immune responses to trauma reviewarticle. Nat Immunol 2018:19:327-41.

25 Abboud A, Namas RA, Ramadan M, Mi Q, Almahmoud K, Abdul-Malak O, Azhar N, Zaaqoq A, Namas R, Barclay DA, et al. Computational analysis supports an early, type 17 cell-associated divergence of blunt trauma survival and mortality. Crit Care Med 2016;44:e1074-81.

26 Lee Y, Awasthi A, Yosef N, Quintana FJ, Xiao S, Peters A, Wu C, Kleinewietfeld M, Kunder S, Hafler DA, et al. Induction and molecular signature of pathogenic Th17 cells. Nat Immunol 2012;13:991-9.

27 Namas RA, Mi Q, Namas R, Almahmoud K, Zaaqoq AM, Abdul-Malak O, Azhar $\mathrm{N}$, Day J, Abboud A, Zamora R, et al. Insights into the role of chemokines, damage-associated molecular patterns, and lymphocyte-derived mediators from computational models of trauma-induced inflammation. Antioxid Redox Signal 2015;23:1370-87

28 Letourneau PA, McManus M, Sowards K, Wang W, Wang Y-wei, Matijevic N, Pati S, Wade CE, Holcomb JB. Aged plasma transfusion increases mortality in a rat model of uncontrolled hemorrhage. J Trauma 2011;71:1115-9.

29 Matijevic N, Wang Y-WW, Kostousov V, Wade CE, Vijayan KV, Holcomb JB. Decline in platelet microparticles contributes to reduced hemostatic potential of stored plasma. Thromb Res 2011;128:35-41. 